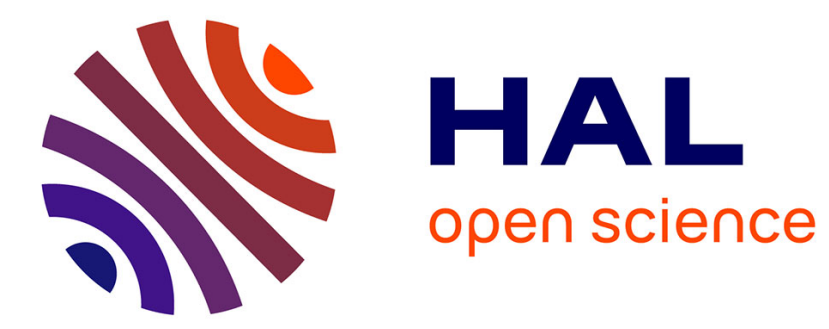

\title{
Access towards enantiopure $\alpha, \alpha$-difluoromethyl alcohols by means of sulfoxides as traceless chiral auxiliaries
}

\author{
Chloé Batisse, Armen Panossian, Gilles Hanquet, Frédéric Leroux
}

\section{To cite this version:}

Chloé Batisse, Armen Panossian, Gilles Hanquet, Frédéric Leroux. Access towards enantiopure $\alpha, \alpha-$ difluoromethyl alcohols by means of sulfoxides as traceless chiral auxiliaries. Chemical Communications, 2018, 54 (74), pp.10423-10426. 10.1039/C8CC05571H . hal-02150060

\section{HAL Id: hal-02150060 \\ https://hal.science/hal-02150060}

Submitted on 14 Dec 2021

HAL is a multi-disciplinary open access archive for the deposit and dissemination of scientific research documents, whether they are published or not. The documents may come from teaching and research institutions in France or abroad, or from public or private research centers.
L'archive ouverte pluridisciplinaire $\mathbf{H A L}$, est destinée au dépôt et à la diffusion de documents scientifiques de niveau recherche, publiés ou non, émanant des établissements d'enseignement et de recherche français ou étrangers, des laboratoires publics ou privés. 


\title{
Access towards enantiopure $\alpha, \alpha$-difluoromethyl alcohols by means of sulfoxides as traceless chiral auxiliaries
}

\author{
Chloé Batisse, Armen Panossian, Gilles Hanquet* and Frédéric R. Leroux*
}

\begin{abstract}
A new methodology to access enantiopure $\alpha, \alpha$-difluoromethyl alcohols is hereby being described. The strategy relies on the use of an enantiopure aryl $\alpha, \alpha$-difluoromethyl sulfoxide employed as chiral and removable auxiliary for the stereoselective difluoromethylation of carbonyl derivatives. The obtained $\alpha, \alpha$ difluoro- 6 -hydroxysulfoxides displayed unprecedented diastereomeric ratios.
\end{abstract}

Whether it be in the field of pharmaceutical, agrochemical, polymer or electronics research, fluorine plays an increasingly important role in our daily lives. ${ }^{1}$ This is illustrated by more than 200 pharmaceuticals and 155 agrochemicals currently commercialised containing at least one fluorine atom. ${ }^{2}$ The current interest for this element can be explained by the fact that the presence of fluorine atoms or fluorinated groups in bioactive molecules can deeply modify their physical, chemical and biological properties. ${ }^{3}$ Several methods describing the introduction of fluorinated moieties have therefore been reported in the literature so far. ${ }^{4}$ However, the synthesis of highly enantioenriched fluorinated molecules remains a huge challenge for organic chemists.

In contrast to enantioselective fluorination or trifluoromethylation, the stereoselective introduction of a difluoromethyl group is in its infancy. ${ }^{5}$ Yet, compared to the other currently used fluorinated moieties, the more recent $\mathrm{CHF}_{2}$ group provides additional advantages ${ }^{6}$ making it a lipophilic bioisostere of hydroxyl, thiol and amine groups. ${ }^{3}$ Recently, Lippard and his co-workers underlined that, besides altering the metabolic stability and acidity of a molecule, the $\mathrm{CHF}_{2}$ moiety can be considered as a good hydrogen bond donor influencing intramolecular interactions and conformational preference. ${ }^{7}$

As far as enantioenriched $\alpha, \alpha$-difluoromethyl alcohols are concerned, their synthesis has not been widely explored yet. They can be accessed through bio- or organometallic-catalysed reduction of the corresponding $\alpha, \alpha$-difluoro ketones, ${ }^{8}$ through pallado-catalysed reductive coupling $^{9}$ or even by using enantioselective difluoromethylation involving naked $\mathrm{CHF}_{2}{ }^{-}$ anion surrogates in presence of different chiral quaternary ammonium salts, ${ }^{5}$ among others. ${ }^{10}$ Even though such methods sometimes give access to high enantioselectivities, their major drawback lies in their usually high substrate-dependence.

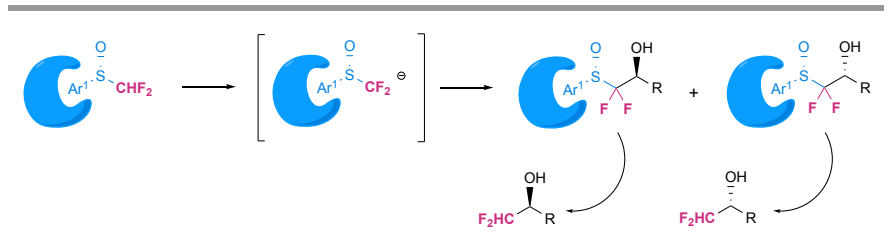

Figure 1. Methodology to access to $\alpha, \alpha$-difluoromethyl alcohols by means of an enantiopure $\alpha, \alpha$-difluoromethyl sulfoxide
Inspired by these results and by the need for overcoming this impactful substrate dependence, the use of a chiral equivalent of the difluoromethyl anion was considered to synthesise such $\alpha, \alpha$-difluoromethyl alcohols. Due to our interest in the chemistry of sulfoxides and their versatile properties, ${ }^{11}$ an enantiopure aryl $\alpha, \alpha$-difluoromethyl sulfoxide was proposed as a chiral reagent for the stereoselective difluoromethylation of carbonyl derivatives, leading to diastereo- and enantiopure $\alpha, \alpha$-difluoro- $\beta$-hydroxysulfoxides. This scaffold would afford, upon removal of the chiral auxiliary, highly enantioenriched $\alpha, \alpha$-difluoromethyl alcohols (Figure 1). Interestingly, the corresponding strategy starting from racemic $\alpha, \alpha$ difluoromethyl phenyl sulfoxide had already been validated by $\mathrm{Hu}$, Prakash et al. ${ }^{12} \alpha, \alpha$-Difluoro-6-hydroxy sulfoxides were obtained in their case with excellent yields but limited diastereoselectivity (49:51 to 67:33 d.r.), as observed in the case of non-fluorinated 6 -hydroxysulfoxides, ${ }^{13}$ and the strategy had not been extended to the use of enantiopure sulfoxides. Our group thus had to address both issues to ensure an efficient access to a series of highly enantioenriched $\alpha, \alpha$ difluoromethyl alcohols. To the best of our knowledge, only one method has been reported to synthesise enantiopure aryl $\alpha, \alpha$-difluoromethyl sulfoxides. Yagupolskii and his co-workers indeed prepared optically active $\alpha, \alpha$-difluoromethyl sulfoxide 3b with $98 \%$ e.e.. ${ }^{14}$ However, due to the tedious multi-step sequence required which also showed low reproducibility and to ensure atom economy and time saving, it was decided to investigate for another efficient pathway to synthesise such enantiopure aryl $\alpha, \alpha$-difluoromethyl sulfoxides.

A three-step process to access racemic sulfoxides $\mathbf{3 a}$ and $\mathbf{3 b}$ was first optimised to start addressing these issues (Scheme 1). Racemic sulfoxides are usually obtained through oxidation of the corresponding sulfides with, for instance, Selectfluor ${ }^{\circledR}, 15$ or usually $m$-CPBA at low temperature. ${ }^{16}$ It was decided, in our strategy, to use periodic acid in presence of a catalytic amount of iron trichloride at room temperature. This method, developed by Kim et al. on non-fluorinated compounds, ${ }^{17}$ is a good alternative to other oxidants since it prevents the overoxidation into the corresponding sulfone. A combination of $\mathrm{H}_{2} \mathrm{O}_{2} /$ TFA $^{18}$ could also lead to the expected sulfinyl acetates with good yields and without side products. Decarboxylation of acetate $\mathbf{2} \mathbf{b}$ was optimised under both thermal and microwave conditions. It allowed us to access the corresponding racemic $\alpha, \alpha$-difluoromethyl sulfoxides $\mathbf{3} \mathbf{a}$ and $\mathbf{3} \mathbf{b}$ under mild conditions. 

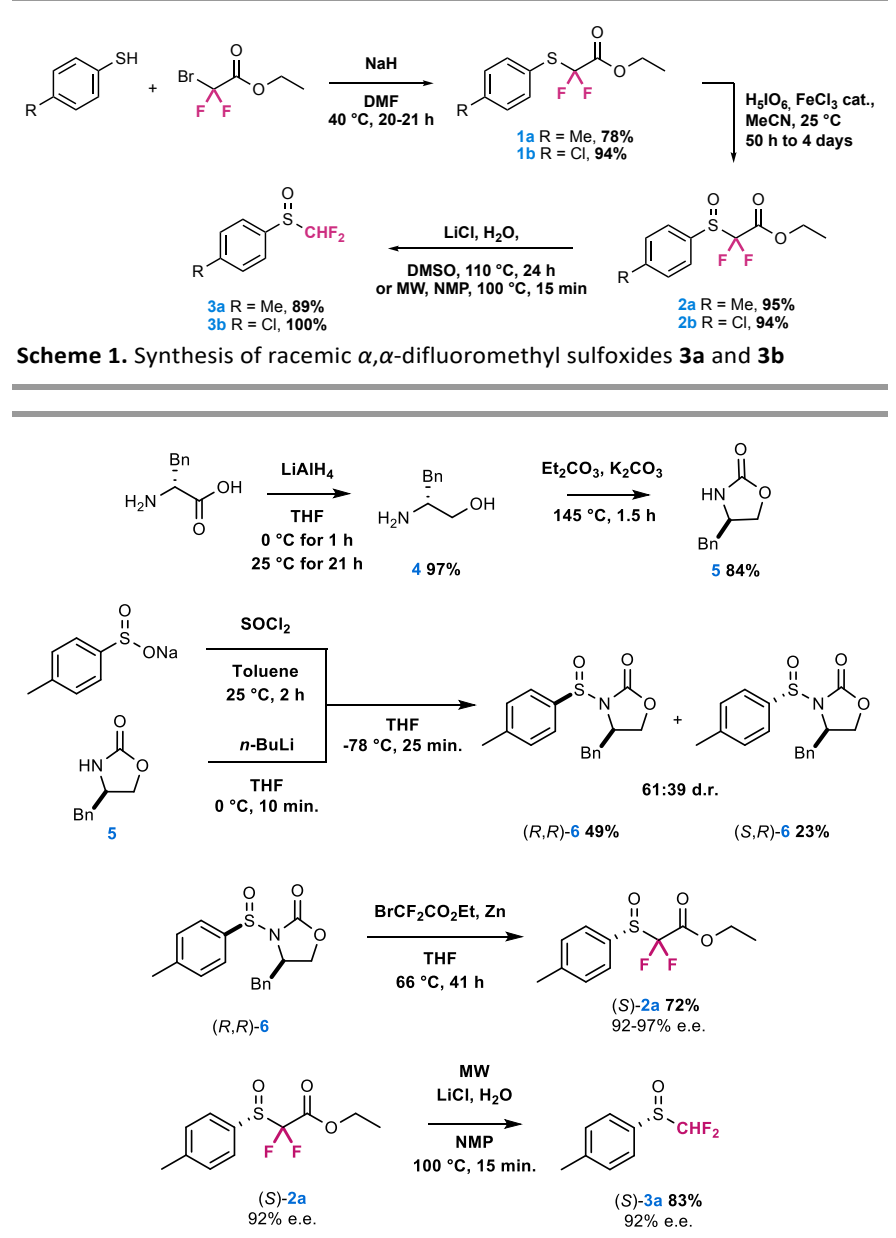

Scheme 2. Synthesis of enantiopure $\alpha, \alpha$-difluoromethyl sulfoxide (S)-3a

On the basis of existing methods by which enantiopure nonfluorinated sulfoxides are synthesised, ${ }^{19}$ several attempts including enantioselective sulfoxidations or Reformatsky-type reactions were performed for the purpose of accessing enantiopure aryl $\alpha, \alpha$ difluoromethyl sulfoxides. These trials unfortunately turned out fruitless. However, as $N$-sulfinyloxazolidinones are known to be efficient chiral sulfinyl transfer reagents, ${ }^{20}$ a Reformatsky-type reaction using ethyl bromodifluoroacetate and enantiopure sulfinyl oxazolidinone $(R, R)-6$ was carried out and allowed us to obtain the desired enantioenriched sulfinyl acetate (S)-2a with very satisfactory yield and enantioselectivity (resp. $77 \%$, up to $97 \%$ e.e., Scheme 2). Enantioenriched $\alpha, \alpha$-difluoromethyl sulfoxide (S)-3a was then obtained through decarboxylation under microwave conditions without racemisation of the sulfoxide. It is noteworthy that a $90 \%$ e.e. batch of compound (S)-3a could be enriched up to $97 \%$ e.e. by crystallisation from $\mathrm{Et}_{2} \mathrm{O}$ allowing us to confirm its predicted configuration (see ESI for crystallographic structure).

Having the desired $\alpha, \alpha$-difluoromethyl sulfoxide in hand under racemic or highly enantioenriched forms, we first adapted $\mathrm{Hu}$ and Prakash's procedure ${ }^{15}$ as starting point to determine the best conditions in terms of conversion and diastereoselectivity for the synthesis of $\alpha, \alpha$-difluoro- $\beta$-hydroxysulfoxides. Starting with racemic sulfoxide $3 \mathrm{a}$ and using two equivalents of $t$-BuOK, hydroxysulfoxide 7a was obtained with poor d.r. in either THF or DMF (resp. 40:60 and 53:47 d.r., Procedure A, Entries 1 and 2, Table 1). We could observe, by ${ }^{19} \mathrm{~F}$ NMR, that the minor diastereomer switches to the major one by using THF as solvent instead of DMF. Another base was then employed for the generation of the (toluenesulfinyl)difluoromethyl anion, namely Schwesinger's base ( $\left.\mathrm{P}_{4} t-\mathrm{Bu}\right)$. This base has indeed already been successfully used to deprotonate fluoroform or difluoromethyl phenyl sulfide prior to addition onto electrophiles, without collapse of the fluoroalkyl anion into the corresponding fluorocarbenoid, usually observed upon use of alkaline or alkaline earth metal bases..$^{21}$ Moreover, using $\mathrm{P}_{4} t$-Bu would have additional advantages. In contrast to $\mathrm{Li}, \mathrm{K}$ or $\mathrm{Mg}$ cations, the non-coordinating $\left[\mathrm{P}_{4} t-\mathrm{Bu} / \mathrm{H}\right]^{+}$counterion would, on the one hand, render the difluoro( $p$-toluenesulfinyl)methyl anion more reactive, leading to an earlier transition state for the attack onto the carbonyl carbon. Accordingly, the latter would have a rather planar $\mathrm{sp}^{2}$-like geometry in the T.S., versus a more $\mathrm{sp}^{3}$-like tetrahedral geometry in the case of a late T.S., with the carbon substituents being more remote from the incoming nucleophile and exerting a less pronounced steric hindrance. Consequently, when using the superbase, one would expect a more efficient relay of the chiral information from the sulfoxide to the newly created stereocentre, and thus a possibly higher stereoselectivity of the reaction. Actually, such a positive effect of a phosphazene superbase on stereoselectivity was demonstrated by Solladié-Cavallo et al. in the reaction of related methyl sulfones with aldehydes. ${ }^{22}$ On the other hand, one would expect, in the case of $\mathrm{Li}, \mathrm{K}$ or $\mathrm{Mg}$ cations, a pre-coordination of the carbonyl electrophile to the cation, leading to a cyclic 6membered T.S., thus establishing a preferred orientation of the electrophile with regard to the $O$-coordinated ${ }^{23}$ sulfoxide anion. With the non-coordinating $\left[\mathrm{P}_{4} t-\mathrm{Bu} / \mathrm{H}\right]^{+}$ion, such a pre-association is not possible, and a different relative orientation of the dipoles of the nucleophile and of the carbonyl electrophile, hence a different stereoselectivity, could be expected. When $\mathrm{P}_{4} t$-Bu was introduced in the reaction mixture as a commercially available solution in hexane, the experiment carried out in THF as solvent afforded a promising d.r. of 84:16 (Procedure B, Entry 3, Table 1). Moreover, and to our delight, hydroxysulfoxide $7 \mathrm{a}$ was obtained with excellent selectivity (up to 99:1 d.r.) with 2 equiv. of $\mathrm{P}_{4} t$-Bu in hexane, when both sulfoxide and electrophile were solubilised in DMF (Procedure B, Entry 4, Table 1). However, subsequent tests in DMF afforded variable d.r. (between 55:45 and 99:1), presumably due to the formation of aggregates in the reaction mixture. In order to circumvent the solubility issues of commercial $\mathrm{P}_{4} t$-Bu in DMF, the superbase was solubilised in freshly distilled THF and added to the reagents dissolved in freshly distilled THF (Procedure C, Entry 5, Table 1). Reproducible diastereomeric ratios could be obtained in this way (99:1 d.r., Entry 5, Table 1). Conditions of Entry 5 were therefore chosen for further experiments.

Table 1. Survey of reaction conditions

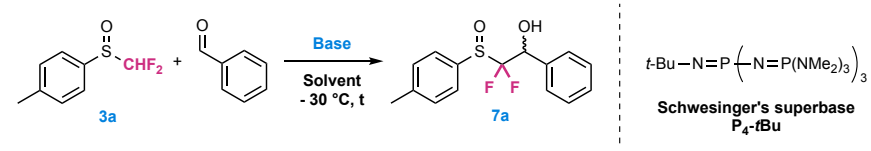




\begin{tabular}{ccccc}
\hline Entry & $\begin{array}{c}\text { Base } \\
\text { (2 equiv.) }\end{array}$ & Solvent & Time & d. $\mathbf{r}^{a}$ \\
\hline $\mathbf{1}$ & \multirow{2}{*}{-BuOK $^{b}$} & $\mathrm{THF}$ & $40 \mathrm{~min}$ & $40: 60$ \\
$\mathbf{2}$ & & $\mathrm{DMF}$ & $2 \mathrm{~h}$ & $53: 47$ \\
$\mathbf{3}$ & $\mathrm{P}_{4} t-\mathrm{Bu}^{c}$ & $\mathrm{THF}$ & $2 \mathrm{~h}$ & $84: 16$ \\
$\mathbf{4}$ & $\mathrm{DMF}$ & $2 \mathrm{~h}$ & $55: 45$ to $99: 1$ \\
$\mathbf{5}$ & $\mathrm{P}_{4} t-\mathrm{Bu}^{d}$ & $\mathrm{THF}$ & $2 \mathrm{~h}$ & $99: 1$ \\
\hline
\end{tabular}

a Diastereomeric ratios were determined by ${ }^{19} \mathrm{~F}$ NMR and confirmed by reversedphase HPLC $-b$ Procedure A: potassium tert-butoxide was solubilised in the solvent of the reaction $-c$ Procedure $B$ : $\mathrm{P}_{4} t-\mathrm{Bu}$ was used as a commercially available solution in hexane $-{ }^{d}$ Procedure $\mathrm{C}$ : $\mathrm{P}_{4} t-\mathrm{Bu}$ was added as a solution in freshly distilled THF. See ESI for more information.

A ${ }^{19} \mathrm{~F}$ NMR monitoring of the reaction performed under such conditions (Entry 5, Table 1) showed an increasing d.r. over time (See ESI for additional information). We ascribe this outcome to a kinetic resolution, where one diastereoisomer of the intermediate alcoholate would preferably undergo an additional deprotonation by the superbase, with subsequent formal elimination of HF and formation of the corresponding mono fluorinated $\alpha$-fluoro- 6 -ketosulfoxide, observed on NMR spectra of the crude mixtures (Scheme 3, see ESI for more details). It should be highlighted that such results were not observed in the case of LiHMDS or $t$-BuOK as bases, ${ }^{15}$ which would concord with the insufficient basicity of the latter with regard to $\mathrm{P}_{4} t$-Bu for $C$-deprotonation of the carbinol.

A screening on different aromatic, heteroaromatic and aliphatic aldehydes and ketones was then performed using the optimised conditions (Figure 2). Interestingly, diastereoselectivities ranking from 69:31 to 99:1 were obtained for some compounds (7a, 7d-f, $\mathbf{7 g}, \mathbf{7 j}$ and $\mathbf{7 m}$ ). Although the crude ${ }^{19} \mathrm{~F}$ NMR spectra showed good d.r., they also revealed the presence of the corresponding $\alpha$-fluoro8 -ketosulfoxides $\mathbf{8}$, thus confirming that the obtention of better d.r. is related to the formation of these side products. Concerning the reactions of ketones as electrophiles, diastereoselectivities were low (7b and 7l, resp. 56:44 and 60:40 d.r.). This might be explained by the fact that the generated $\alpha, \alpha$-difluoro- $\beta$-hydroxysulfoxides cannot be deprotonated in $\alpha$ position, supporting our proposed mechanism. Moreover, the moderate yields associated to the good diastereoselectivities often further corroborate this assumption.

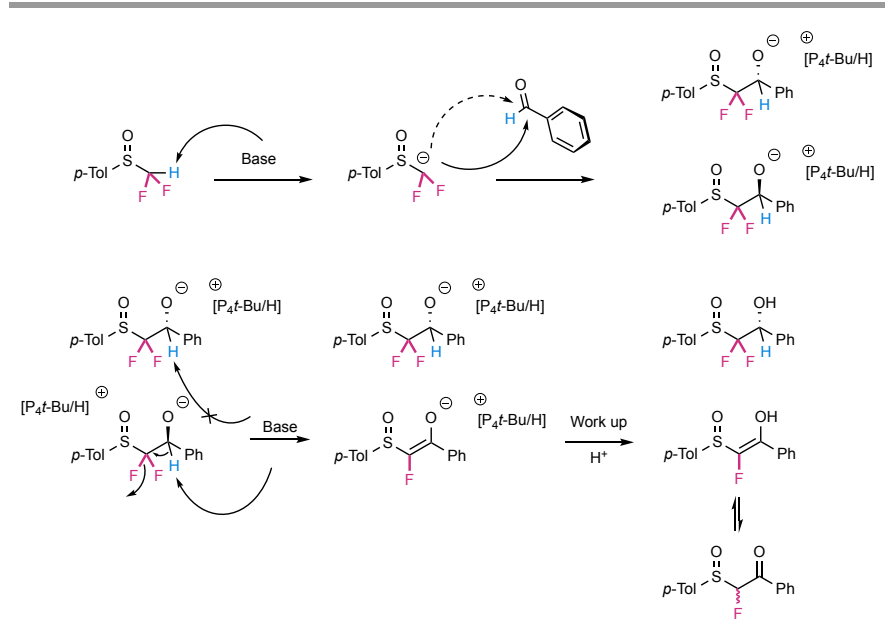

Scheme 3. Proposed mechanism to explain the good diastereoselectivities

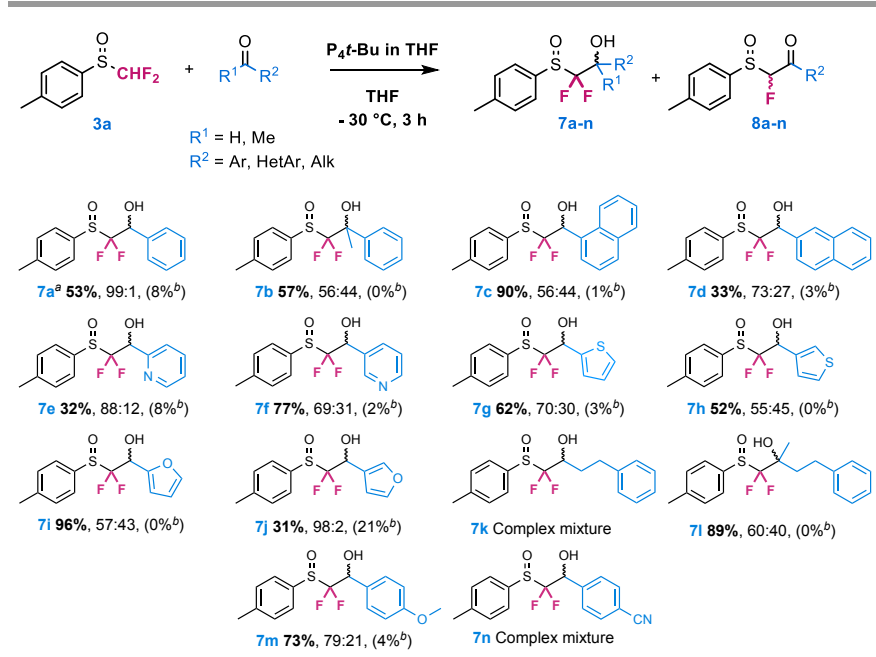

Diastereomeric ratios were determined by ${ }^{19} \mathrm{~F}$ NMR on the crude mixtures a Reaction was carried out for 2 hours - b The percentages of $\alpha$-fluoro- 6 ketosulfoxides $8 \mathrm{a}-\mathrm{n}$ were determined by ${ }^{19} \mathrm{~F}$ NMR on the crude mixtures.

Figure 2. Screening of different electrophiles

The use of enantiopure $\alpha, \alpha$-difluoromethyl sulfoxide (S)-3a ( $97 \%$ e.e.) and benzaldehyde allowed us to obtain compound $\left(S_{S}\right)-7 a$ with excellent selectivities (97:3 d.r., $97 \%$ e.e. of the major diastereomer, $43 \%$ yield, Scheme 4). It was finally possible to obtain $\alpha, \alpha$-difluoro- 6 -hydroxysulfone $9 a$ by oxidising sulfoxide $\left(S_{s}\right)-7 a$ with $m$-CPBA. According to the conditions described by $\mathrm{Hu}$ and co-workers, ${ }^{10}$ highly enantioenriched difluoromethylated alcohols can be obtained with retention of configuration through desulfonylation of these $\alpha, \alpha$-difluoro- 6 -hydroxysulfones using magnesium metal in an acetate buffer (Scheme 4). ${ }^{24}$

In conclusion, a new efficient stereoselective pathway to highly enantioenriched $(97 \%$ e.e.) $\alpha, \alpha$-difluoromethyl sulfoxides by using $N$-sulfinyloxazolidinones has been developed. These sulfoxides can be employed as chiral difluoromethanide equivalents to synthesise highly enantioenriched $\alpha, \alpha$-difluoromethyl alcohols. We observed that the phosphazene superbase has a strong impact on the diastereomeric ratios of the $\alpha, \alpha$-difluoro- $\beta$-hydroxysulfoxides (up to 99:1 d.r.) formed through the condensation of the sulfoxide difluoromethyl anion onto different aldehydes. Further experiments are currently in progress to unravel the causes of such unprecedented diastereoselectivities. Alternately, using two equivalents of potassium tert-butoxide also provides the desired product, albeit with lower diastereoselectivity, but as a mixture of separable diastereomers, thereby allowing to overcome the expensive cost of the nevertheless recyclable phosphazene superbase. 


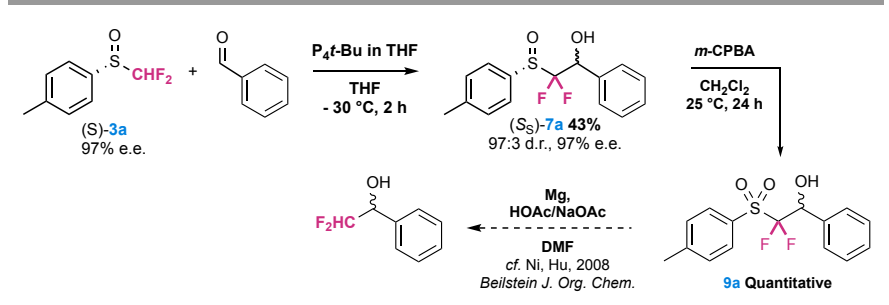
Scheme 4. Synthesis of 6 -hydroxysulfoxide $\left(S_{S}\right)$-7a from enantiopure $(S)$ -
difluoromethyl $p$-tolyl sulfoxide $(S)$-3a, oxidation and and stereo-retentive desulfonylation

We thank the Centre National de la Recherche Scientifique (CNRS) and the University of Strasbourg and are very much grateful to the International Centre for Frontier Research in Chemistry (ICFRC) for a project grant to C.B. The French Fluorine Network (GIS Fluor) is also acknowledged.

\section{Conflicts of interest}

The authors declare no conflicts of interest.

\section{Notes and references}

1 Bioorganic and Medicinal Chemistry of Fluorine, Wiley, 2008; P. Maienfisch and R. G. Hall, Chimia, 2004, 58, 93; Fluorine and the Environment: Agrochemicals, Archaeology, Green Chemistry and Water, Elsevier Science, 2006; K. Müller, C. Faeh and F. Diederich, Science, 2007, 317, 1881.

2 Modern Synthesis Processes and Reactivity of Fluorinated Compounds: Progress in Fluorine Science, Elsevier Science, 2016; T. Fujiwara and D. O'Hagan, J. Fluorine Chem., 2014, 167, 16; J. Wang, M. Sánchez-Roselló, J. L. Aceña, C. del Pozo, A. E. Sorochinsky, S. Fustero, V. A. Soloshonok and H. Liu, Chem. Rev., 2014, 114, 2432.

3 S. Purser, P. R. Moore, S. Swallow and V. Gouverneur, Chem. Soc. Rev., 2008, 37, 320; P. Jeschke, ChemBioChem., 2004, 5, 570; B. E. Smart, J. Fluorine Chem., 2001, 109, 3; H.-J. Böhm, D. Banner, S. Bendels, M. Kansy, B. Kuhn, K. Müller, U. ObstSander and M. Stahl, ChemBioChem., 2004, 5, 637; K. L. Kirk, J. Fluorine Chem., 2006, 127, 1013; N. A. Meanwell, J. Med. Chem., 2011, 54, 2529.

4 C. D. Murphy and G. Sandford, Expert Opinion on Drug Metabolism \& Toxicology, 2015, 11, 589; S. Barata-Vallejo, B. Lantaño and A. Postigo, Chem. Eur. J., 2014, 20, 16806; T. Liang, C. N. Neumann and T. Ritter, Angew. Chem. Int. Ed., 2013, 52, 8214; K. L. Kirk, Org. Proc. Res. Dev., 2008, 12, 305; G. Landelle, A. Panossian, F. R. Leroux, Curr. Top. Med. Chem., 2014, 14, 941.

5 N. Shibata, S. Mizuta and H. Kawai, Tetrahedron: Asymmetry, 2008, 19, 2633; X. Yang, T. Wu, R. J. Phipps and F. D. Toste, Chem. Rev., 2015, 115, 826.

6 M. A. Chowdhury, K. R. A. Abdellatif, Y. Dong, D. Das, M. R. Suresh and E. E. Knaus, J. Med. Chem., 2009, 52, 1525.

7 C. D. Sessler, M. Rahm, S. Becker, J. M. Goldberg, F. Wang and S. J. Lippard, J. Am. Chem. Soc., 2017, 139, 9325.

8 W. Borzęcka, I. Lavandera and V. Gotor, J. Org. Chem., 2013, 78, 7312; K. Nakamura and R. Yamanaka, Tetrahedron: Asymmetry, 2002, 13, 2529; S. V. Slungard, T.-A. Krakeli, T. H. Kane Thvedt, E. Fuglseth, E. Sundby and B. H. Hoff, Tetrahedron, 2011, 67, 5642.

9 K. Aikawa, S. Yoshida, D. Kondo, Y. Asai and K. Mikami, Org. Lett., 2015, 17, 5108.

10 S. Goushi, K. Funabiki, M. Ohta, K. Hatano and M. Matsui, Tetrahedron, 2007, 63, 4061; K. Kato, H. Nakamura and K.
Nakanishi, Applied Surface Science, 2014, 293, 312; C. Ni, F. Wang and J. Hu, Beilstein J. Org. Chem., 2008, 4, 21.

11 G. Solladié, G. Hanquet, I. Izzo and R. Crumbie, Tetrahedron Lett., 1999, 40, 3071; G. Solladié, X. J. Salom-Roig and G. Hanquet, Tetrahedron: Asymmetry, 2000, 41, 2737; G. Hanquet, X. J. Salom-Roig, L. Gressot-Kempf, S. Lanners and G. Solladie, Tetrahedron: Asymmetry, 2003, 14, 1291; G. Hanquet, F. Colobert, S. Lanners, G. Solladié, ARKIVOK, 2003, 7, 328; M. C. Carreño, G. Hernandez-Torres, M. Ribagorda and A. Urbano, Chem. Commun., 2009, 6129; M. C. Carreño, Chem. Rev., 1995, 95, 1717; H. Pellissier, Tetrahedron, 2006, 62, 5559; G. Solladié, Synthesis, 1981, 185.

12 L. Zhu, Y. Li, C. Ni, J. Hu, P. Beier, Y. Wang, G. K. S. Prakash and G. A. Olah, J. Fluorine Chem., 2007, 128, 1241.

13 G.-I. Tsuchihashi, S. Iriuchijima and M. Ishibashi, Tetrahedron Lett., 1972, 13, 4605; A. J. Walker, Tetrahedron: Asymmetry, 1992, 3, 961.

14 A. V. Matsnev, N. V. Kondratenko, Y. L. Yagupolskii and L. M. Yagupolskii, Tetrahedron Lett., 2002, 43, 2949; L. M. Yagupolskii and A. V. Matsnev, Mendeleev Commun., 2006, 16, 132.

15 Y.-M. Lin, W.-B. Yi, W.-Z. Shen and G.-P. Lu, Org. Lett., 2016, 18, 592.

16 G. K. S. Prakash, C. Weber, S. Chacko and G. A. Olah, Org. Lett., 2007, 9, 1863.

17 S. S. Kim, K. Nehru, S. S. Kim, D. W. Kim and H. C. Jung, Synthesis, 2002, 2484.

18 C. G. Venier, T. G. Squires, Y.-Y. Chen, G. P. Hussmann, J. C. Shei, and B. F. Smith, J. Org. Chem., 1982, 47, 3773; K.-M. Chen, Y.-W. Sun, Y.-W. Tang, Z.-Y. Sun and C.-H. Kwon, Mol. Pharm., 2004, 2, 118.

19 P. Pitchen, E. Dunach, M. N. Deshmukh and H. B. Kagan, J. Am. Chem. Soc., 1984, 106, 8188; F. A. Davis, R. T. Reddy, W. Han and P. J. Carroll, J. Am. Chem. Soc., 1992, 114, 1428; H. Egami and T. Katsuki, J. Am. Chem. Soc., 2007, 129, 8940; J. Sun, C. Zhu, Z. Dai, M. Yang, Y. Pan and H. Hu, J. Org. Chem., 2004, 69, 8500; J. Han, V. A. Soloshonok, K. D. Klika, J. Drabowicz and A. Wzorek, Chem. Soc. Rev., 2018, 47, 1307; J. Legros and C. Bolm, Chem. Eur. J., 2005, 11, 1086.

20 D. A. Evans, M. M. Faul, L. Colombo, J. J. Bisaha, J. Clardy and D. Cherry, J. Am. Chem. Soc., 1992, 114, 5977.

21 H. Kawai, Z. Yuan, E. Tokunaga and N. Shibata, Org. Biomol. Chem., 2013, 11, 1446; T. Punirun, D. Soorukram, C. Kuhakarn, V. Reutrakul and M. Pohmakotr, Eur. J. Org. Chem., 2014, 4162; Y. Zhang, M. Fujiu, H. Serizawa and K. Mikami, J. Fluorine Chem., 2013, 156, 367.

22 A. Solladié-Cavallo, D. Roche, J. Fischer and A. De Cian, J. Org. Chem., 1996, 61, 2690.

23 G. Ludwig, T. Rüffer, A. Hoppe, T. Walther, H. Lang, S. G. Ebbinghausa and D. Steinborn, Dalton Trans., 2015, 44, 5323, and references cited therein.

C. Ni and J. Hu, Tetrahedron Lett., 2005, 46, 8273. 